\title{
Qualitative approaches in mathematics education re- search: challenges and possible solutions
}

\author{
Sashi Sharma \\ Department of Mathematics, Science and Technology Education, Faculty of Education, The university of Waikato, Hamilton, New Zea- \\ land
}

\section{Email address:}

sashi@waikato.ac.nz (S. Sharma)

\section{To cite this article:}

Sashi Sharma. Qualitative Approaches in Mathematics Education Research: Challenges and Possible Solutions, Education Journal. Vol. 2, No. 2, 2013, pp.50-57. doi: 10.11648/j.edu.20130202.14

\begin{abstract}
Despite being relatively new in mathematics education research, qualitative researchapproaches need special attention as attempts are being made to enhance the credibility and trustworthiness of this approach. It is important that researchers are aware of the limitations associated with these methods so that measures are put in place to try and minimize the effects of these limitations Philosophical roots and key features of this paradigm are outlined. Qualitative methods such as the interview approach in research literature as a data gathering tool are considered next. Challenges faced by qualitative researchers in terms of reliability, validity and generability are considered. Examples are provided to illustrate methodological problems and solutions related to qualitative methods.
\end{abstract}

Keywords: Research Methods, Qualitative Research, Data Collection, Quality Criteria, Limitations, Possible Solutions

\section{Introduction}

In the last two decades, a new paradigm widely referred to as interpretative research paradigm has begun to dominate research in mathematics education. Merriam(1998) traces the philosophical roots of this paradigm to the interpretative school of thought which considers education to be a process and school a lived experience. Reality (knowledge) is constructed socially by individuals through social interactions in their everyday life experiences (Bryman, 2008; Cohen, Manion\& Morrison. 2007). There are multiple interpretations of single events and situations, hence knowledge is multi-layered and complex (Cobb, 2007). This paradigm provides a general perspective on knowledge and research that allow researchers to select specific methods for particular projects (Cobb, 2007; Ernest, 1997). There has been a growing trend in mathematics education for researchers to use qualitative approaches. As Silver (2004, p. 154)stated, "One might argue that researchers in mathematics education have in recent decades erected a monument to qualitative research methods and non experimental mode of inquiry."

Although there is often an emphasis on qualitative methods, quantitative methods can also be used when required.In many studies (Shaughnessy, 2007; Watson \&Callingham, 2003) researchers have gathered and quanti- fied results of surveys on mathematics tasks in large numbers but have also conducted interviews with smaller number of students. Hypotheses generated about why students were answering survey questions in particular ways were validated in detailed interviews. Interviews often revealed lines of thought that were often missed in the survey data by researchers (Kalinowski, Lai, Fidler, \& Cumming, 2010; Shaughnessy, 2007).

Although qualitative methods have become common in mathematics education research, questions linger about their soundness. For instance, it is often mis-associated with terms such as subjective or biased (KalinowskiLai, Fidler, \& Cumming, 2010).

In discussing these challenges, Groth (2010, p. 7) writes: "Although qualitative methods have helped the fields of mathematics and statistics education move forward, and are still employed in current studies, the usefulness of qualitative studies is still frequently debated in political and scholarly discourse. Questions about qualitative research that were addressed during its rise to prominence among mathematics education researchers have re-surfaced in recent policy documents written by governmental agencies and scholars in the field."

Gergen and Gergen (2000) write that there is a growing dissatisfaction among some qualitative researchers for moving away from scientific standards or being too positiv- 
ist. They add that in response to this criticism many educational researchers do not provide adequate or clear justifications for their methods, findings and conclusions. Some research scientists believe that that anything goes in qualitative studies. For instance, this issue is echoed in Labschagne's (2003) abstract: For many scientists used to doing quantitative studies the whole concept of qualitative research is unclear, almost foreign, or airy fairy- not real research.

The purpose of this paper is to highlight some of the issues raised about qualitative research and address them by drawing upon examples from my own studies. The paper begins by describing features of qualitative approaches. Qualitative methods such as the interview approach in research literature as a data gathering tool are considered next. Challenges faced by qualitative researchers in terms of reliability, validity and generability are considered. I illustrate how I endeavored to meet these in the example studies.

\section{Features of Qualitative Research}

As with all research in education, there are different interpretations and definitions for qualitative research. It is alternatively called naturalistic inquiry, field study, case study, participant observation and ethnography (Bryman, 2008; Merriam, 1998; Yin, 2003). According to Creswell (2008), qualitative researchers collect data in the field site. They do not bring individuals in a contrived situation. Researchers collect data themselves by examining documents and behaviour or interviewing participants. The researcher keeps a focus on the meanings that the participants hold about the problem or issue. For example, in a mathematics classroom, data is collected as students interact in small groups, during whole-class discussions, interact with the teacher, or working individually. In qualitative approaches, researchers are regarded as data collection instruments and have an important role. Their values, assumptions, beliefs, and knowledge have an influence on the data that is collected.Hence it is important to acknowledge that the data could be glossed with the meanings and purposes of researchers and researchers.

Another feature of qualitative research is that it provides depth and detail through direct quotations and descriptions of situations, events, interactions and observed behaviors (Labuschagne, 2003). The data can be analysed using an open ended approach (Cohen, Manion and Morrison, 2007). In such an open ended approach the data can be analysed with respect to the research questions and the theories posed by the researcher as well astheories of what is occurring that can come out of the data itself. Qualitative researchers build their patterns, categories and themes from the bottom up by organizing data into more abstract units of information (Braun and Clarke, 2006). This involves working back and forth between the themes and the database until the researcher has established a comprehensive set of themes. Themes can then be used to find, classify and compare incidents so a clear account can be given of the re- search.

\section{Data Gathering Tools in Qualitative Inquiry}

In qualitative research, interviewing, observations and document analysis are the major source of the qualitative data for understanding the phenomenon under study (Drew, Hardman, and Hosp, 2008; Fontana and Frey, 2005). Interviews provide an opportunity for the researcher to investigate ideas and beliefs of participants further and to gather data which may not have been obtained by other methods such as observation or survey (Cohen et al., 2007; Shaughnessy, 2007).

The interview method takes the form of a dialogue in which the researcher seeks to elicit information from the subject about how the latter thinks. Usually, the discussion is centred upon a task or problem which has been carefully chosen to give the respondent every opportunity to display behaviour from which mental mechanisms used in thinking about that task can be inferred. Depending on the purpose of the interview, interview questions can be highlystructured, semi-structured, or open-ended. Additionally, the researcher's familiarity with and knowledge about the exploratory or confirmatory nature of the study determines the structure of the interview questions. Important aspects in interviews include maintaining a relaxed manner, asking clear questions, note-taking, appropriate use of follow-up question or probes, establishing trust, and keeping track of responses (Cohen, Manion and Morrison, 2000; Drew et al, 2007).

Although the interview has a number of important advantages over other data collection techniques, it does have definite limitations as a research tool (Hunting, 1983). McCormick and James (1988) note that both interviewers and respondents are sources of bias, the former through the questions they ask, or their perceived role and presence, the latter through their conception of the interview, their memory of the event, their ability to answer and their motivation in taking part in the interview. They suggest that whatever procedure for collecting data is selected, it should always be examined critically to assess to what extent it is likely to be reliable and valid. There are some specific issues with regards to interviews in the school context. Trust and respect are key issues in the research, especially with Pasifika research participants (Anae, Coxon, Mara, Wendt-Samu and Finau, 2001). Language is also an issue as participants in the research may have English as a second language.

Observations involve collecting qualitative information about human actions and behaviours in social activities and events in a real social environment, such as classroom teaching and learning (Cohen et al., 2011; Neuman, 2007). There are two main observation strategies: participant observation and non-participant observation (Bryman, 2008; Cohen et al., 2011; Johnson \& Christensen, 2012). Participant observation is when the researcher becomes part of the 
group under study and participates in everyday social activities of that social system to obtain the actual feelings and experiences of the phenomena, while at the same time taking notes of the actions and behaviours of the participants. The observer as a participant can inform the participants of the study about his or her participation in the social activity (Bryman, 2008; Cohen, Manion\& Morrison, 2011).

In contrast, a non-participant observation technique involves the researcher sitting or standing on the side while social activities like teaching and learning are taking place, both inside and outside the classrooms (Bryman, 2008; Cohen et al., 2011).

Analysing documents is a form of collecting qualitative information from a primary or original source of written, printed and recorded materials to answer the research questions in interpretive case studies (Creswell, 2009; Lincoln \&Guba, 1985; Punch, 2009). The documents provide evidence of authentic or real activities undertaken by human beings in social organisations and human thinking. The documents may include letters, plans, models, daily operational schedules, personal diaries, reports and photographs of activities (Punch, 2009).

\section{Challenges Faced By Qualitative Re- search Methods}

Despite the strengths attributed to qualitative research approaches (Golafshani, 2003);Groth, 2010), it is important that researchers be aware of the limitations associated with these methods so that measures are put in place to try and minimize the effects of these limitations. Anfara, Brown and Mangione. (2002) state that too often qualitativeinquiry is evaluated against the positivist criteria such as validity and reliability and found to be lacking in some or all of these criteria.

Lankshear and Knobel (2004) identified two different approaches tdemonstrating the trustworthiness of qualitative research. The traditional approach is to try to show that qualitative studies can satisfy the quality control criteria to which quantitative studies are traditionally held. The second, more recent approach is to use a different, unique set of criteria (Golafshani, (2003);Lesh, 2002; Morse et al., 2002; Parker, 2004; Simon, 2004).

The traditional approach to assessing qualitative research is often associated with positivism (Cobb, 2007; Ernest, 1997; Kalinowski,Lai, Fidler, \& Cumming, 2010; Morse et al., 2002; National Research Council, 2002). Qualitative researchers embracing positivism generally seek to demonstrate the quality of their studies by showing that they satisfy standards for various types of validity, generalizabilityand reliability by which quantitative studies are judged. Guidebooks exist with suggestions on how to adapt these elements of quality control for use in qualitative studies (Cresswell, 2008; Kalinowski,Lai, Fidler, \& Cumming, 2010; Miles \&Huberman, 1994; Morse et al., 2002).

The second approach to assessing qualitative research re- jects positivistic criteria as being overly simplistic and restrictive. The authors (Battista et al. 2009; Lesh, 2002) claim that qualitative research can not be subjected to the same criteria as quantitative approaches. Lesh suggests that off-the-shelf definitions such as reliability, validity and replicability that were appropriate in the past may not be relevant to modern research in mathematics education. According to Lesh, it is more reasonable to use closely related criteria such as usefulness, meaningfulness and shareabilityThose embracing the newer approach often advocate the view that traditional standards for assessing quantitative research are insufficient for qualitative research because of its fluid and evolving nature. Elliott et al. (1999) proposed a set of seven guidelines for qualitative research. Since the two approaches to assessing qualitative research outlined above rest upon different ontological assumptions, it is not possible to identify a universally accepted framework for responding to charges that qualitative research is inherently inferior to quantitative. Some strategies for doing so reflect positivist assumptions whereas others reject them. Elements of both approaches are considered below to provide credibility checks in qualitative studies.

Reliability is a measure of consistency over time and over similar samples, the extent to which a procedure produces similar results under constant conditions on all occasions with the same person or across interviewers (Cohen et al., 2007)). A question which produces one type of response on one occasion but a different response on another is considered unreliable. Cohen et al., (2000) point out that qualitative researchers tend to view reliability as a fit between what they record as data and what actually occurs in the natural setting rather than accurate measurements between different observations. Two researchers studying a single setting may come up with different data and produce different findings, but both studies can be considered reliable. Lesh(2002, p. 35) asks the following question:

"When a given student is not expected to perform in the same way on a series of similar tasks, what does it mean to speak about reliability in which repeated measurements are assumed to vary around the student's true (invariant) understandings and abilities that are assumed to apply equally to all tasks?"

According to Burns (2000) reliability in qualitative research can be enhanced if researchers outline the reasons for the research and the major question they want to address, they explicate their perspectives on the question, stating their research assumptions and biases, explain their data gathering procedures and categories developed for analysis. However, Anfara et al. (2000) explain that including information on the decisions that are made during the process of constructing qualitative research is part of responding to the question of whether not the findings are credible and trustworthy. They offer three suggestions for assessing the methodological rigor and analytical defensibility of the qualitative paradigm: designing interview questions that address research questions, conducting data analysis through code mapping and verifying findings and 
data triangulation. Triangulation helps to demonstrate that the phenomenon that has been observed is not merely a product of the instrument or method used in the study. Triangulation occurs when two or more strategies of data gathering and/or sources of data are used to illustrate a coherent picture of a phenomenon under study (Cohen et al., 2011; Patton, 2002). Two types of triangulation that have relevance to this paper are: data triangulation and triangulation of method. Data triangulation refers to multiple data that are gathered from more than one source with participants, over a longer period of time to see the reality. The triangulation of method is when the study uses two or more strategies to gather data on the same issue or topic.

Closely related to the concept of reliability is validity. Like reliability, it is concerned with errors that may occur in the research process. It is particularly concerned with whether an item measures or describes what it is supposed to measure or describe (Bell, 1993). McCormick and James (1988) write that qualitative researchers, because they try to understand the experiences of their informants in naturalistic settings, believe their methods bring them closer to reality and are, therefore, more valid or at least ecologically valid (that is valid for a specific group or place). Patton (2002) argues that validity in qualitative research methods is largely dependent upon the skill, competence and rigour of the researcher. For instance, threats to validity in interviewing can be minimised by decreasing the number of incorrect interpretations through asking interviewees whether inferences drawn from what has been said are correct. Hunting (1983) suggests steps to maximise content relevance and the representativeness of the selected tasks. He argues that content validity can be achieved by analysing proposed tasks in terms of the content stated to be appropriate for various age levels in prominent curriculum documents.

Researchers use the term generalizability to refer to whether the findings of a study hold up beyond the setting or individuals under study (Bell, 1993; Burns, 2000). Critics of qualitative research point out that a major disadvantage of in-depth qualitative study is that generalisation is not possible beyond the population under study. Many forms of qualitative research share the view that notions of validity and generalizability are established in different ways from traditional criteria used when referring to the transfer and application of findings from one setting to another. Qualitative research does not aim to generalize findings but to understand a specific situation. Attention is on the local setting and unique context, rather than on generalizing the findings. Bell (1993) argues that researchers concerned with the question of generalizability may draw upon other studies to establish the representativeness of what they have found, or they may conduct a larger number of less intense mini-studies. Most researchers highlight the importance of making the work of teaching and learning open to critique of the wider community (Drew et al., 2008; Groth, 2010; Watson, 2002). Making work available for public examination supports the improvement of the re- searcher's practice and increases the chance that the work becomes useful to other mathematics educators.

Below I briefly illustrate how I endeavored to achieve quality criteria in my study.

\section{Achieving Quality Criteria in Qualit- ative Research: Sharma (1997)}

A concern about students' difficulties with statistics and probability and a lack of research in this area outside of western countries led to my study (Sharma, 1997). Information was gathered about how form five (14 to 16 yearolds) Fijian-Indian students construct ideas about statistics. Overall, the research addressed the question:

"What ideas do Form Five Fijian students have about statistics and probability, and how do they construct these?

The study comprised a series of face-to-face interviews in a typical secondary school with a sample of differing abilities and attitudes. See Figure 1 for an example of interview questions used in the study. Each student was interviewed individually by myself in a room away from the rest of the class. Each interview lasted between 40 to 50 minutes. All interviews were recorded on audio tape and transcribed for analysis. Data also comprised of classroom observations and student work as students participated in a statistics unit taught by the class teacher.

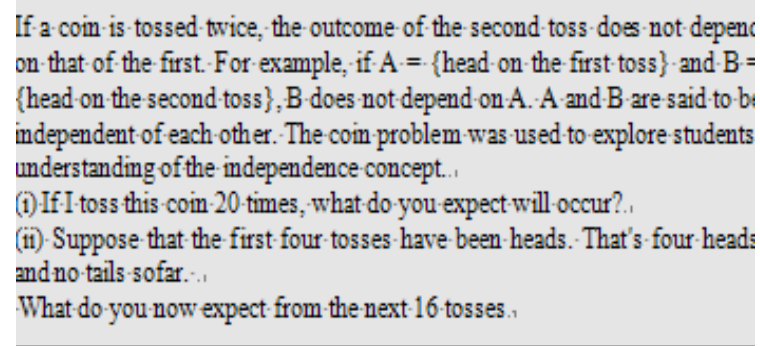

Figure 1. Interview question with description of construct.

\section{Dealing with Issues of Quality Crite- ria}

Kalinowski et al. (2010).suggest that whatever procedure for collecting data is selected, it should always be examined critically to assess to what extent it is likely to be valid and reliable. This section outlines how these issues were addressed in my study.

To aid validity the study made use of some of the view points mentioned by Anfara et al. (2000) and (Cresswell, 2008). Research questions provided scaffolding throughout my study. Since in-depth interviews were used as primary data-gathering source, the interview questions were crossreferenced to the content stated to be appropriate for various age levels in the curriculum document (Fijian Ministry of Education, 1994) and the construct being investigated (See Figure 2). 


\begin{tabular}{lll}
\hline Construct & $\begin{array}{l}\text { Curriculum } \\
\text { Reference }\end{array}$ & Interview Question \\
\hline $\begin{array}{l}\text { Independence of } \\
\text { events }\end{array}$ & $\begin{array}{l}\text { Exploring probability } \\
\text { in everyday contests }\end{array}$ & A3, A4 \\
\hline
\end{tabular}

Figure 2. Interview construct/question with curriculum reference.

The appropriateness of these interview tasks for the Fijian students was established by checking them with the class teacher and the HOD mathematics at the school.

Most of the aspects outlined by Burns (2000) and Cresswell (2008) were incorporated in the research. A rationale for the study (importance of statistics in society, difficulties in statistical reasoning and a lack of research in this area) and the major questions addressed were outlined in chapter one. Researcher perspectives on the project (background, expectations) were outlined inthe report. Additionally, to aid reliability and minimise interviewer bias, the study employed a semi-structured approach. Each student interviewed was initially confronted with an identical task. During the interview, care was taken to avoid leading the students towards any particular view point, so responses to questions were accepted as they were given and probing questions were asked simply to ascertain the reasons for what the student thought. My prior experiences and familiarity with the interview approach enabled me to use supplementary questions to check whether the interpretations constructed by me fitted with the student construction. In some cases, students were asked to comment on the transcripts to ensure that the meaning constructed by me was the same as that constructed by the students.

Thematic analysis (Braun, \& Clarke, 2006) was used to analyse theinterview data in my study. The phases with descriptionare outlined in Table 1.

Table 1. Phases ofdata analysis.

\begin{tabular}{ll}
\hline Phase & Description of the process \\
\hline Familiarizing myself with the data & $\begin{array}{l}\text { This involved listening to the audio- } \\
\text { tapes in an active way, transcribing } \\
\text { and translating (in some cases) da- } \\
\text { ta,reading and re-reading the data } \\
\text { set, noting down initial ideas } \\
\text { This phase involved coding interest- } \\
\text { ing features of the data in a systemat- } \\
\text { ic fashion across the entire data set. } \\
\text { See Figure } 3 \text { for an example of codes } \\
\text { applied to a segment of data for } \\
\text { independence task. Since coding was } \\
\text { done manually, notes were written } \\
\text { on the text to identify segments of } \\
\text { data. Once all the data were coded, } \\
\text { data relevant to each code was col- } \\
\text { lated in separate files. } \\
\text { This phase involved sorting codes } \\
\text { into potential categories and gather- } \\
\text { ing all data relevant to eachcategory. }\end{array}$ \\
\hline Searching for themes
\end{tabular}

\begin{tabular}{ll}
\hline & A table was used to help sort the \\
different codes into categories. & This phase involved checking if the \\
themes worked in relation to the \\
coded extracts and theentire data. \\
There was anongoing analysis to \\
refine the specific of each category \\
and the overall story the analysis \\
told. See Figure 4 for identification \\
naming themes \\
and names for each category. \\
Appropriate extracts were related \\
back to the analysis, research ques- \\
tions and literature to produce a \\
report.
\end{tabular}

\begin{tabular}{|c|c|}
\hline Data extract & Code \\
\hline $\begin{array}{l}\text { When we to s s coins or things like } \\
\text { that we will be not sure whether } \\
\text { we will be getting same or } \\
\text { different all the time. So we } \\
\text { have to make a guess. }\end{array}$ & Chance is unpredictable \\
\hline $\begin{array}{l}\text { It depends on how you throw. If you } \\
\text { put down heads and then throw } \\
\text { you get a head. }\end{array}$ & $\begin{array}{l}\text { The results depend on } \\
\text { individual controlof the coin }\end{array}$ \\
\hline $\begin{array}{l}\text { It depends on how fast yout } \\
\text { hrow... in physics we are told } \\
\text { it will swing and change directions }\end{array}$ & $\begin{array}{l}\text { Experiences from other } \\
\text { learning areas }\end{array}$ \\
\hline
\end{tabular}

Figure 3. An example of codes applied to a segment of data for independence construct.

\begin{tabular}{ll}
\hline Category & Properties of category \\
\hline & $\begin{array}{l}\text { Beliefs: the results depend } \\
\text { on individual control or s ome } \\
\text { outside factor such as luck }\end{array}$ \\
Experiences: other leaming \\
Non-statistical & $\begin{array}{l}\text { Fres or everyday life situations } \\
\text { Partial-statistical }\end{array}$ \\
& $\begin{array}{l}\text { Representativenes } \\
\text { Equiprobability bias } \\
\text { Language difficulties }\end{array}$ \\
\hline
\end{tabular}

Figure 4. Categories with properties (Sharma, 1997).

My research report is grounded in examples. It provide verbatim examples of student responses. These examples could invite the readers to appraise my interpretations and think aboutother ways the data could have been interpreted.

Researchers use the term generalizability to refer to whether the findings of a study hold up beyond the setting or individuals under study. I acknowledge that the findings of my study may not be generalizable to all settings because students in other areas and countries are likely to have very different experiences and hence their reasoning would differ. However, since I was alert to the possible threats to generalizability, the results from other studies have been used to establish the representativeness of the findings. The purpose of my research was to build on what 
had already been done by others. Amir and Williams (1999), Fischbein, and Schnarch (1997),Jones, Langrall, and Mooney(2007) and Shaughnessy(2007, 1992) raised the concerns about the lack of probability research outside of western countries. Shaughnessy advocated small scale studies that incorporate the strong ethnic influence that culture has on students' probabilistic reasoning. My study addressed some of these shortcomings. Additionally, since one of the purposes of the study was to identify general patterns of reasoning, findings gained from the study are likely to be of some importance to other groups. A four-step framework based on empirically grounded results was developed during the study which others can adjust to their local circumstances. The framework will contribute to the refinement of conceptual models developed in earlier researchand assist teachers by providing a rubric for teaching and assessing students.

The data reported in my study was mostly obtained from the individual interviews. Data from classroom observations and student written work were used to check initial findings, to fill gaps, and to informally triangulate the findings. In some cases students moved from appropriate strategies to inappropriate ones when responding to the interview tasks. One of the factors that could have made students change in this way was the students' experiences as learners at school. Student reasoning is not questioned in class. The teacher's concern is whether they give correct answers. If the students give correct answers it is accepted by the teacher. Students are only questioned when they give wrong answers. It seems probable that in my research, the students interpreted my probing as an indication that something was wrong with their answers and so they quickly switched to a different strategy. Obtaining data from interviews and classroom observations helped me to more fully understand the particular incidents such as switching strategy.

I collected the interview data by interacting face-to-face with the participants and physically observing their behaviour and actions in their classrooms. As the research was with people, I endeavoured to create mutual understanding and a healthy relationship in my daily interactions with the participants. As I integrated with the participants, the power relationship was flattened, and the "researcher" became one of the participants. I upheld the culture, values, beliefs and norms of the school during the study.

The information gathered was initially written up as a doctoral thesis and then turned into articles to be sent to national and international journals for publication. Since the work was accessible, the wider community, scholars and policy makers would all benefit from this project.

\section{Conclusion}

The value of qualitative research in advancing the field of mathematics education should not be underestimated. It provides a means for conducting scientific studies that contribute to our understanding of mathematics teaching and learning. One of the strengths of qualitative research is that participants' behaviour is recorded in natural settings, with all the intricacies of the environment operating. Qualitative research is also particularly useful for in-depth study of a small group of people. Despite the strengths attributed to qualitative research approaches, it has been criticised for lack of reliability, validity and generalizability and intersubjectivity. In qualitative research it may be difficult to understand what is going on due to the complexity of the natural settings. It is important that researchers be aware of the limitations associated with these methods so that measures are put in place to try and minimize the effects of these limitations. The paper offers some suggestions for enhancing the reliability, validity and generalizability of qualitative research methods. Qualitative researchers need to provide enough depth and clarity so that someone else is able to judge the quality of study and accept or refute the findings.

Finally, I support the views expressed by Kalinowski, Lai, Fidler, and Cumming(2010) that both quantitative and qualitative methods are to some extent biased, and both can be done well or poorly. However, it appears that usually qualitative studies are subjected to criitcisms of subjectivity and transparency. Given the potential of qualitative research to contribute to the field of mathematics, future discussions would do well to avoid elevating one above but to focus upon what each approach can contribute to our collective understanding about the teaching and learning of mathematics.

\section{References}

[1] Amir, G. \& Williams, J. (1999). Cultural Influences on Children's Probabilistic Thinking. Journal of Mathematical Behavior, 18 (10), 85-107.

[2] Anae,M., Coxon, E., Mara, D., Wendt-Samu, T. \&Finau, C. (2001). Pasifika Education Research Guidelines Final Report: Auckland: Uniservices.

[3] Anfara, V. A., Brown, M \&Mangione T. L. (2002). Qualitative Analysis on Stage: Making the Research Process More Public.Educational Researcher, 31, (7), 28-38.

[4] Battista, M, Boerst, T. Confrey, J, Knuth, E. Smith, M. Sutton, J. White, D \&Quander, (2009). Research in Mathematics Education: Multiple Methods for Multiple users, Journal of Research in mathematics Education, 40(3), 216-240.

[5] Bell, J. (1993). Doing Your Research Project. Buckingham, Philadelphia: Open

[6] Braun, V, \&Clarke, V. (2006). Using thematic analysis in psychology, Qualitative Research in Psychology, 3. 77-101.

[7] Bryman, A. (2008). Social research methods ( $3^{\text {rd }}$ ed.). Oxford, NY: Oxford University.

[8] Butterfield, J. (2009). Using grounded theory and action research to raise attainment in, and enjoyment of, reading. Educational Psychology in Practice, 25(4), 315-326.

[9] Burns, R. B. (2000). Introduction to research methods $\left(4^{\text {th }}\right.$ 
ed.). Melbourne, Victoria, Australia: Longman.

[10] Cobb, P. (2007). Foundations 1. Putting Philosophy to Work: Coping With Multiple Theoretical Perspectives. In F. K. Lester(, Jr Ed.), Second Handbook of Research on Mathematics Teaching and Learning (pp1-38). Reston: The National Council of Teachers of Mathematics.

[11] Cohen, L., Manion, L., \& Morrison, K. (2007). Research methods in education $\left(6^{\text {th }}\right.$ ed.). London, UK: Routledge.

[12] Cohen, L., Manion, L., \& Morrison, K. (2011). Research methods in education ( $7^{\text {th }}$ ed.). Abingdon, Oxon, NY: Routledge.

[13] Corbin, J., \& Strauss, A. (2008). Basics of qualitative research (3rd ed.). Thousand Oaks,CA: Sage.

[14] Cresswell, J. W. (2008). Educational Research: Planning, Conducting, and Evaluating Quantitative and Qualitative Research. Upper Saddle River, NJ: Pearson Prentice Hall.

[15] Cronbach, L. J. (1975). Beyond the two disciplines of scientific psychology. AmericanPsychologist, 30(2), 116-127.

[16] Davies, D., \& Dodd, J. (2002). Qualitative research and the question of rigor. QualitativeHealth Research, 12(2), 279289.

[17] Drew, C. J., Hardman, M. L. \&Hosp, J. L. (2008). Designing and Conducting Research in Education. LA: Sage Publications.

[18] Elliott, R., Fischer, C., \&Rennie, D. (1999). Evolving guidelines for publication ofqualitative research studies in psychology and related fields. British Journal ofClinical Psychology, 38(3), 215-229.

[19] Ernest, P. (1997). The Epistemological Basis of Qualitative Research in Mathematics Education: A Postmodern Perspective Journal for Research in Mathematics Education. Monograph, Vol. 9, 22-177.

[20] Fijian Ministry of Education, Women, Culture,Science and Technology (1994). PrimaryMathematics Prescriptions. Suva: Curriculum Development Unit.

[21] Fischbein, E. \&Schnarch, D. (1997). 'The evolution with age of probabilistic, intuitively based misconceptions', Journal for Research in Mathematics Education 28, 96-105.

[22] Fontana, A. \& Frey, J. H.(2005). The interview: From neutral stance to political involvement. In N. K. Denzin\& Y. S. Lincoln (Eds.), The Sage Handbook of Qualitative Research (pp.695-725)..London: Sage Publications.

[23] Gergen, M. M. \&Gergen, K. J. (2000). Qualitative inquiry: Tensions and transformations. In N. K. Denzin\& Y. S. Lincoln (Eds.), Handbook of Qualitative Research (pp.10251046)..Thousand Oaks, CA: Sage Publications.

[24] Golafshani, N. (2003). Understanding reliability and validity in qualitative research. TheQualitative Report, 8(4), 597607.

[25] Growth, R. (2010). Situating qualitative modes of inquiry within the discipline of statistics education research Statistics Education Research Journal, 9(2), 7-21, http://www.stat.auckland.ac.nz/serj

[26] Guba, E. G. \& Lincoln, Y. S. (1994). Competing paradigms in qualitative research. In N. K. Denzin and Y. S. Lincoln
(Eds) Handbook of Qualitative Research(pp. 105-117). London: Sage Publications.

[27] Hunting, R. (1997). Clinical interview methods in mathematics education research and practice. Journal of Mathematical Behavior, 16(2), 145-165.

[28] Hunting, R. P. (1983). Emerging methodologies for understanding internal processes governing children's mathematical behaviour. The Australian Journal of Education, 27(1), 45-61.

[29] Johnson, B., \& Christensen, L. (2008). Educational research: Quantitative, qualitative and mixed approaches ( ${ }^{\mathrm{rd}}$ ed.). Los Angles, CA: Sage.

[30] Jones, G. A., Langrall, C. W..\&Mooney, E. S.(2007). Research in probability: Responding to classroom realities.In F. K. Lester Jr (Ed.), Second Handbook of Research on Mathematics Teaching and Learning (pp 909-955). Reston: The National Council of Teachers of Mathematics.

[31] Kalinowski, P., Lai, J., Fidler, F. \& Cumming, G. (2010). Qualitative research: an essential part of statistical cognition research Research Journal, 9(2), 22-34, http://www.stat.auckland.ac.nz/serj

[32] Labuschagne, A. (2003, March). Qualitative research - Airy fairy or fundamental? The Qualitative Report, 8(1). Retrieved [26/7/2010], from http://www.nova.edu/ssss/QR/QR8-1/.html

[33] Lankshear, C., \&Knobel, M. (2004). A handbook for teacher research: From design toimplementation. Berkshire: Open University Press.

[34] Lesh, R. (2002). Research design in mathematics education: Focusing on design experiments.In L. D. English (Ed.), Handbook of International Research in Mathematics Education (pp 27 - 49). New Jersey: Lawrence Erlbaum Associates.

[35] McCormick, R. \& James, J. (1988). Curriculum Evaluation in Schools. London: Croom Helm.

[36] Miles, M. B., \&Huberman, A. M. (1994). Qualitative data analysis (2nd ed.). ThousandOaks, CA: Sage

[37] Merriam, S. (1998). Qualitative research and case study applications in education. San Francisco: Josey-Bass.

[38] Morse, J. M., Barrett, J. M., Mayan, M., Olson, K., \&Spiers, J. (2002). Verificationstrategies for establishing reliability and validity in qualitative research. InternationalJournal of Qualitative Methods, 1(2), 13-22.

[39] National Mathematics Advisory Panel. (2008). Foundations for success: The final reportof the National Mathematics Advisory Panel. Washington, DC: U.S. Department ofEducation.[Online:

http://www.ed.gov/about/bdscomm/list/mathpanel/report/fin al-report.pdf ]

[40] National Research Council. (2002). Scientific research in education. Washington, DC:National Academy Press.No Child Left Behind Act of 2001. (2002). Pub. L, No. 107-110, 115 Stat. 1425. Pfannkuch, M. (2006). Comparing box plot distributions: A teacher's reasoning. Statistics

[41] Neuman, W. L. (2007). Basics of social research: Qualitative and quantitative approaches $\left(2^{\text {nd }}\right.$ ed. $)$. Boston, MA: Al- 
lyn\& Bacon.

[42] Parker, I. (2004). Criteria for qualitativeresearch in Psychology. Qualitative Research in Psychology, 1, 95-106.

[43] Patton, M. Q. (2002). Qualitative evaluation and Research Methods (3 rd edition). London: Sage

[44] Punch, K. F. (2009). Introduction to research methods in education. London, UK: Sage.

[45] Sharma, S. (2010). Qualitative methods in statistics education research: methodological problems and possible solutions.In C.Reading (Ed.) Proceedings of the 8th International Conference on the Teaching of Statistics, Ljubljana, Solvenia: International Statistical Institute and International Association for Statistical Education. Available from

[46] Http://Www.Stat.Auckland.Ac.Nz/ Iase/Publications

[47] Sharma, S. (1997). Statistical ideas of high school students: Some findings from Fiji. Unpublished doctoral thesis. Waikato University, Hamilton, New Zealand

[48] Shaughnessy, J. M.(2007). Research on statistics learning and reasoning.In F. K. Lester(, Jr Ed.), Second Handbook of Research on Mathematics Teaching and Learning (pp 957-
1009). Reston: The National Council of Teachers of Mathematics.

[49] Shaughnessy, J. M. (1992). Research in probability and statistics: Reflections and directions. In D. Grouws (Ed) Handbook of research on mathematics teaching and learning(pp. 465-494). New York: Macmillan.

[50] Silver, E. S. (2004) Ella minnow pea: An allegory for our times? Journal for Research inMathematics Education, 35(3), 154-156.

[51] Simon, M. A. (2004). Raising issues of quality in mathematics education research.Journal for Research in Mathematics Education, 35(3), 157-163.

[52] Watson, J. M. (2002). Doing research in statistics education: More than just data. The Sixth International Conference in Teaching Statistics (ICOTS 6). Cape Town: South Africa.

[53] Watson, J. M. \&Callingham R. (2003). Statistical literacy: A complex hierarchical construct. Statistics Education Research Journal, 2(2), 3-46.

[54] Yin, R. K. (2003). Applications of case study research ( $2^{\text {nd }}$ ed.). Thousand Oaks, CA: Sage. 